\title{
An essential microRNA maturing microprocessor complex component DGCR8 is up-regulated in colorectal carcinomas
}

\author{
Bora Kim $\cdot$ Jae-ho Lee $\cdot$ Jong Wook Park • \\ Taeg Kyu Kwon • Seong Kyu Baek• \\ Ilseon Hwang • Shin Kim
}

Received: 13 February 2013/ Accepted: 30 May 2013/Published online: 18 June 2013

(C) The Author(s) 2013. This article is published with open access at Springerlink.com

\begin{abstract}
MicroRNAs (miRNAs) regulate gene expression through degradation and/or translational repression of target mRNAs. Dysregulations in the miRNA machinery may be involved in carcinogenesis of colorectal cancer (CRC). The purpose of the current study was to evaluate the DiGeorge syndrome critical region gene 8 (DGCR8) and argonaute 2 (AGO2) mRNA expression in CRC and to evaluate the value of clinical parameters on their expression. We investigated the mRNA expressions of DGCR8 and AGO2 in $60 \mathrm{CRC}$ tissues and adjacent histologically non-neoplastic tissues by using quantitative real-time PCR. Our study revealed that the mRNA expression level of DGCR8 is up-regulated in CRC. However, AGO2 mRNA expression was not significantly altered in CRC tissues. Neither DGCR8 nor AGO2 mRNA expression level was
\end{abstract}

Bora Kim and Jae-ho Lee contributed equally to this work.

B. Kim · J. W. Park · T. K. Kwon · S. Kim $(\varangle)$

Department of Immunology, School of Medicine,

Keimyung University, 1095 Dalgubeoldaero, Dalseo-Gu,

Daegu 704-701, South Korea

e-mail: god98005@dsmc.or.kr

J. Lee

Department of Anatomy, School of Medicine,

Keimyung University, 1095 Dalgubeoldaero, Dalseo-Gu,

Daegu 704-701, South Korea

S. K. Baek

Department of Surgery, School of Medicine,

Keimyung University, 1095 Dalgubeoldaero, Dalseo-Gu,

Daegu 704-701, South Korea

I. Hwang

Department of Pathology, School of Medicine,

Keimyung University, 1095 Dalgubeoldaero, Dalseo-Gu,

Daegu 704-701, South Korea not associated with any clinical parameters, including age, tumor stage, CEA titer, and BMI in CRC cases. However, the mRNA expression levels of DGCR8 and AGO2 were positively correlated to each other. This study demonstrated for the first time that the DGCR8 mRNA expression level was up-regulated in CRC, suggesting its important role in pathobiology of colorectal carcinogenesis.

Keywords MicroRNA biogenesis - Colorectal cancer . DGCR8 - AGO2

\section{Introduction}

Colorectal cancer (CRC) is a malignant tumor that originates from the epithelium of colon and rectum and the third most common incident cancer among men worldwide [1]. It has been reported that the five leading primary cancer sites were the stomach, colon and rectum, lung, liver, and prostate in male during 2009 in Korea [2]. In Korea, annual percentage changes of CRC incidence in age-standardized incidence rates were $6.8 \%$ in men between 1999 and 2009 using the world standard population as a standard population [2]. The pathogenesis of CRC is intricate and tightly regulated mechanisms, which involve the accumulation of both genetic and epigenetic alterations in the proliferating cells [3].

In recent years, gradually accumulating evidences have demonstrated that a wide range of biological processes such as cellular development, differentiation, proliferation, cell death, metabolism, and carcinogenesis are associated with a group of endogenous, small (approximately 17 nucleotides), and noncoding RNAs called microRNAs (miRNAs) [4-6]. The biogenesis of miRNA occurs in a well-organized process, referred to as the "miRNA 
machinery" [7]. The microprocessor complex mediates intranuclear biogenesis of precursor miRNAs from the primary miRNA transcript. Extranuclear, mature miRNAs are incorporated into the RNA-induced silencing complex (RISC) before interaction with complementary target mRNA that leads to protein translational repression or mRNA destabilization [8, 9]. The DiGeorge syndrome critical region gene 8 (DGCR8) is a part of microprocessor complex and has been shown to be essential for miRNA maturing [10]. The argonaute 2 (AGO2) protein is a constituent of a complex protein designated as RISC [11]. Previous study has demonstrated that DGCR8 mRNA expression level is down-regulated in prostate cancer [12]. Up-regulated mRNA expression level of DGCR8 has been revealed in epithelial skin cancer [8] and pleomorphic adenomas of the salivary gland [13]. It has been reported that the AGO2 mRNA expression level is up-regulated in epithelial skin cancer [8]. Though Papachristou et al. [7] studied the mRNA expression levels of Dicer, Drosha, and $\mathrm{AGO} 2$ in CRCs, there are little literatures about the mRNA expression level of DGCR8 and clinicopathologic association in the cancers.

In the present study, we aimed to investigate the mRNA expression levels of DGCR8 and AGO2 in human CRC tissues and corresponding adjacent non-neoplastic tissues from male patients with same cancer, and examined the correlation of the mRNA levels of these miRNA machinery components with various clinicopathologic parameters, including age, tumor stage, BMI, and CEA titer.

\section{Materials and methods}

Patients and tissues

Altogether, sixty male patients diagnosed with CRC were included in the study. Colorectal adenocarcinomas and adjacent non-neoplastic tissues were obtained from the patients undergoing surgery in Dongsan Medical Center (Daegu, Korea) between April 2008 and January 2010. Tissue samples were immediately frozen in liquid nitrogen and stored at $-80{ }^{\circ} \mathrm{C}$ until RNA isolation. Tissue samples were provided from Keimyung Human Bio-resource Bank, Korea. All patients were explained the study purpose, and informed consent was obtained from each study participant. The protocols were approved by the Institutional Review Board of Keimyung University Dongsan Medical Center (approval \#12-41).

RNA and quantitative real-time PCR

Total cellular RNA was extracted from tissues using the TRIzol reagent (Molecular Research Center Inc.,
Table 1 Primer sequences of miRNA machinery components used in quantitative PCR

\begin{tabular}{lll}
\hline Components & Position & Sequence \\
\hline AGO2 & Forward & $5^{\prime}$-TCATGGTCAAAGATGAGATGACAGA-3' \\
& Reverse & $5^{\prime}$-TTTATTCCTGCCCCCGTAGA-3' \\
DGCR8 & Forward & $5^{\prime}$-CAAGCAGGAGACATCGGACAAG-3' \\
& Reverse & $5^{\prime}$-CACAATGGACATCTTGGGCTTC-3' \\
$\beta$-Actin & Forward & $5^{\prime}$-CAGCCATGTACGTTGCTATCCAGG-3' \\
& Reverse & $5^{\prime}$-AGGTCCAGACGCAGGATGGCATG-3' \\
\hline
\end{tabular}

Cincinnati, OH, USA). RNA was quantified using Nanodrop 1000 (Thermo Scientific, Wilmington, Denmark). Each cDNA was synthesized form $2 \mu \mathrm{g}$ of total RNA using M-MLV reverse transcriptase (Promega, Madison, WI, USA) according to the manufacturer's protocol. By using the specific primer pairs described in Table 1 and SYBR GREEN Premix (Toyobo, Japan), quantitative real-time PCR (qPCR) was performed on the LightCycler ${ }^{\circledR} 480$ realtime PCR system (Roche Diagnostics, Mannheim, Germany). $\beta$-Actin was used as a housekeeping gene for normalization, and a no template sample was used as a negative control.

Statistical analysis

Statistical analysis was performed with SPSS 18.0 (SPSS Inc., Chicago, IL, USA). Statistical comparisons for significance were made with Wilcoxon signed-rank test for paired samples. Differences between the groups were analyzed statistically by using Student's $t$ test. The correlations between $D G C R 8$ and $A G O 2$ expressions and clinicopathologic parameters were assessed with the Pearson's correlation coefficient analysis. Generally, $P$ value of $<0.05$ was established to denote significance in all statistical analyses performed in the study.

\section{Results}

Expression levels of DGCR8 and AGO2 mRNA in colorectal cancer tissues and adjacent non-neoplastic colorectal tissues of CRC patients

The mRNA expression levels of DGCR8 and AGO2 were quantified by qPCR in paired specimens of human cancerous colorectal tissues and their respective non-neoplastic colorectal tissues from 60 patients with CRC. The DGCR8 and AGO2 mRNA levels were normalized to the level of $\beta$-actin mRNA. Then, the qPCR data were analyzed by using $\triangle C T$ values [14]. Our study revealed that DGCR8 mRNA expression was significantly higher in carcinomatous tissues than in the corresponding non- 
Fig. 1 The relative DGCR8 mRNA level (normalized to the corresponding $\beta$-actin mRNAs) in tumor tissues compared to adjacent non-cancerous colorectal tissues. Asterisk indicates Wilcoxon signed-rank test
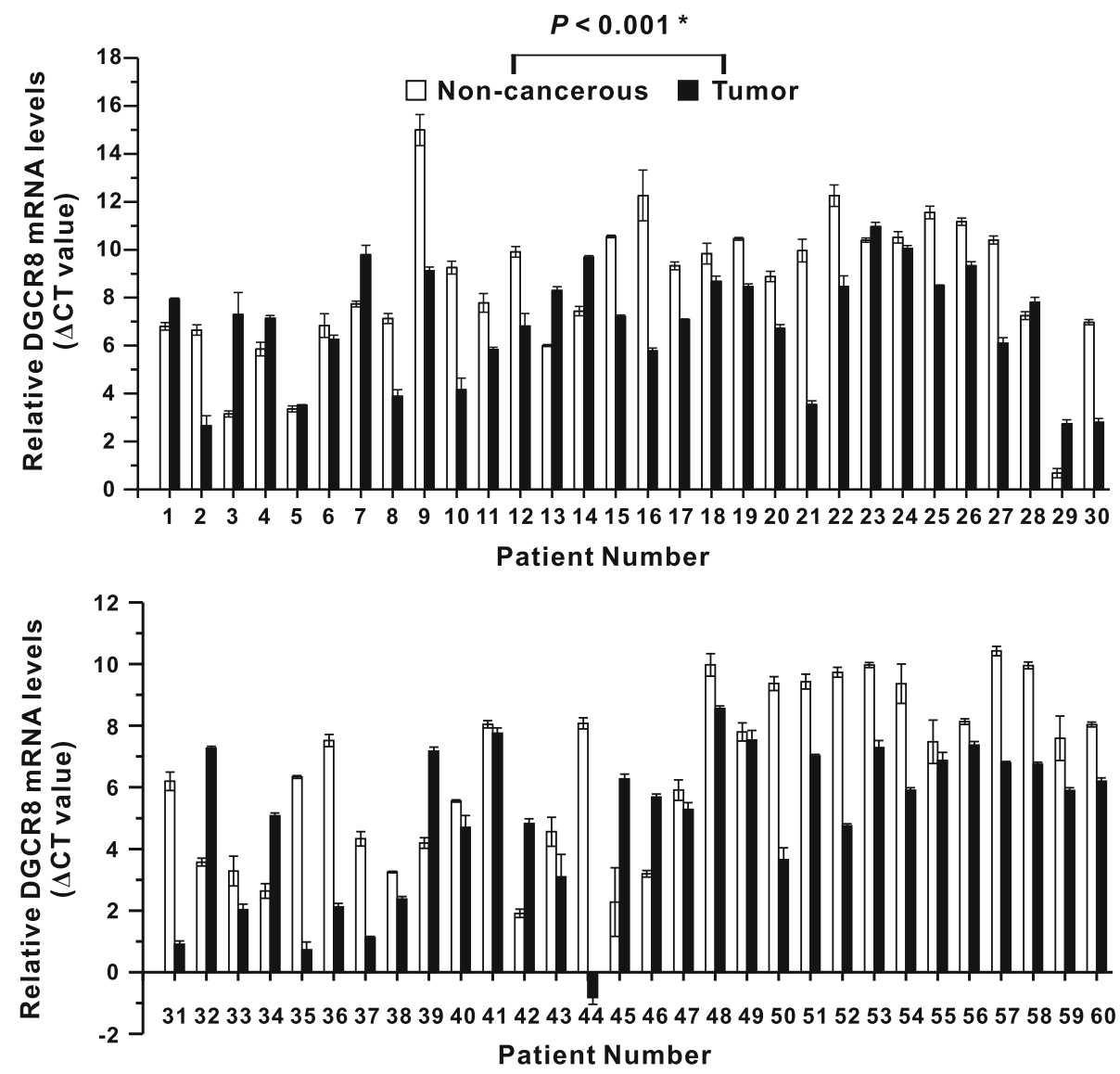

neoplastic tissues in 44 of the 60 patients with CRC $(P<0.001$; Fig. 1). However, AGO2 mRNA expression was not significantly altered $(P=0.259$, Fig. 2$)$. The mean value of DGCR8 mRNA expression level in cancerous tissues was significantly higher than in non-neoplastic colorectal tissues $(P<0.001)$; however, the mean value of AGO2 mRNA expression level was not different between cancerous and non-neoplastic tissues (Fig. 3).

Relationship between DGCR8 and AGO2 mRNA expression levels and the clinical parameters in patients with CRC

The recent study demonstrated that AGO2 is not associated with clinicopathological features, including patient age, gender, and overall survival or tumor location, grade, stage, and size, in CRC [7]. Therefore, we investigated whether the mRNA expression levels of DGCR8 and AGO2 are associated with any clinicopathologic parameters of CRC. Prior to statistical analysis, raw qPCR data of DGCR8 and AGO2 mRNA expression levels were normalized to reference gene, $\beta$-actin. Then, the qPCR data were analyzed by the $2^{-\Delta \Delta C T}$ method [14]. To evaluate the influence of the clinical parameters on mRNA expression of DGCR8 and $\mathrm{AGO} 2$, patients were classified according to each clinical characteristic. The clinicopathologic parameters in 60 patients (mean age: $63.6 \pm 10.4$ years) with CRC according to DGCR8 and AGO2 mRNA expression levels were presented in Table 2. Unfortunately, DGCR8 and AGO2 mRNA expression levels were not statistically associated with age, tumor stage (TNM), CEA titer, and BMI clinical parameters in our CRC specimens. However, higher mRNA expression level of DGCR8 was found in higher group of AGO2 mRNA expression level, and vise versa. Therefore, the mRNA expression levels of DGCR8 and $\mathrm{AGO} 2$ were positively correlated to each other.

\section{Discussion}

MicroRNA pathway is involved in the regulation of various cellular processes, including cellular development, differentiation, proliferation, cell death, metabolism, and carcinogenesis [4-6]. Deregulation of miRNAs in various cancers may be related with altered expression and function of the genes involved in the miRNA machinery components, including DGCR8 [13] and AGO2 [15].

The objectives of this study were to investigate the mRNA expression levels of DGCR8 and AGO2 by RTqPCR method in pair-matched colorectal specimens and 
Fig. 2 The relative AGO2 mRNA level (normalized to the corresponding $\beta$-actin mRNAs) in tumor tissues compared to adjacent non-cancerous colorectal tissues. Asterisk indicates Wilcoxon signed-rank Test
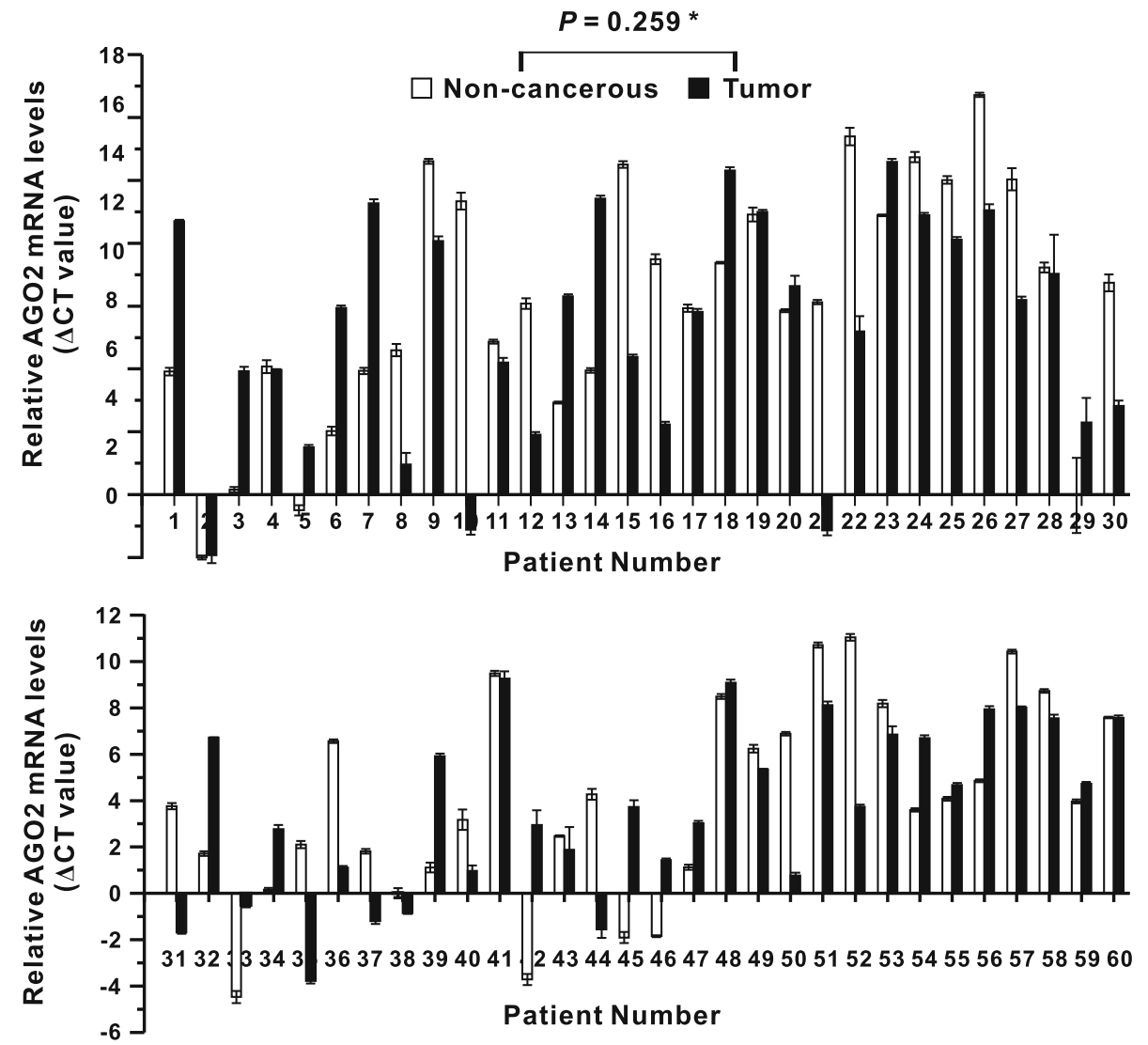

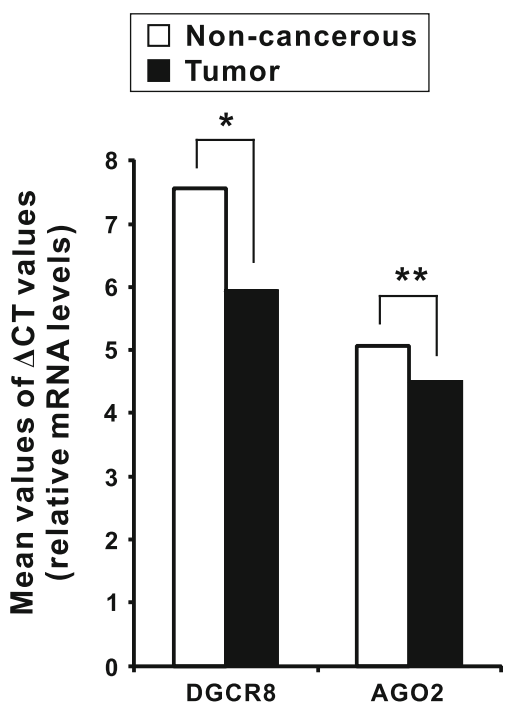

Fig. 3 Relative DGCR8 and AGO2 mRNA expression in CRC group and in the control group; $* P<0.001 ; * * P=0.26$

analyze their correlation with different clinical characteristics. We therefore identified the mRNA expression levels of DGCR8 and AGO2 in CRC tissue compared with adjacent non-neoplastic colorectal tissue in 60 patients with CRC. We determined that DGCR8 mRNA expression level was up-regulated in CRC. Just like the results of our experiment, Sand et al. [8] demonstrated that DGCR8 mRNA expression level was up-regulated in epithelial skin cancers. However, Shaikhibrahim et al. [12] showed also its down-regulation in prostate cancer. DGCR8 is a cofactor for Drosha, an RNAse III endonuclease, and also a part of the microprocessor complex and has been found to be essential for miRNAs maturation [10]. Drosha and DGCR8 have evolved to regulate each other via a complicated double-negative feedback circuit in which DGCR8 stabilizes Drosha through a direct interaction [16]. It thus would be needed to assess the correlation between DGCR8 and Drosha mRNA expression levels in CRC cases. Interestingly, we found the significant association between DGCR8 and AGO2 mRNA expression levels in CRC. This result suggested that DGCR8 and AGO2 may be associated with colorectal carcinogenesis together.

Recently, rapidly accumulating evidence has been shown that perturbation in miRNA biogenesis is closely associated with development and progression of a variety of cancers, including CRC $[7,17,18]$. As one of key enzymes in the miRNA generating process, DICER and DROSHA have been frequently studied [19-25]; however, there was a little study about DGCR8 and AGO2 [8, 26]. Additionally, DGCR8 and AGO2 mRNA expression levels analysis did not even show any significant differences between malignant melanomas (primary cutaneous malignant melanoma and 
Table 2 Correlation of the clinicopathologic parameters with DGCR8 and AGO2 mRNA expression levels in CRCs

\begin{tabular}{|c|c|c|c|c|c|}
\hline Variables & Total & $\mathrm{AGO} 2$ & $P$ & DGCR8 & $P$ \\
\hline Total & $60(100)$ & $29(48.3)$ & & $39(65.0)$ & \\
\hline Age & & & 0.631 & & 0.337 \\
\hline$\leq 50$ & $25(41.7)$ & $13(52.0)$ & & $18(72.0)$ & \\
\hline$>50$ & $35(58.3)$ & $16(45.7)$ & & $21(60.0)$ & \\
\hline BMI & & & 0.901 & & 0.976 \\
\hline$\leq 25$ & 43 (71.7). & $21(48.8)$ & & $28(65.1)$ & \\
\hline$>25$ & $17(28.3)$ & $8(47.1)$ & & $11(64.7)$ & \\
\hline T stage & & & 0.970 & & 0.713 \\
\hline $\mathrm{T} 1$ & $4(6.7)$ & $2(50.0)$ & & $3(75.0)$ & \\
\hline $\mathrm{T} 2$ & $9(15.0)$ & $4(44.4)$ & & $5(55.6)$ & \\
\hline $\mathrm{T} 3$ & $36(60.0)$ & $17(47.2)$ & & $25(69.4)$ & \\
\hline $\mathrm{T} 4$ & $11(18.3)$ & $6(65.5)$ & & $6(54.5)$ & \\
\hline $\mathrm{N}$ stage & & & 0.504 & & 0.405 \\
\hline No & $33(55.0)$ & $14(42.4)$ & & $21(63.6)$ & \\
\hline N1 & $16(26.7)$ & $9(56.3)$ & & $10(62.5)$ & \\
\hline $\mathrm{N} 2$ & $10(16.7)$ & $6(60.0)$ & & $8(80.0)$ & \\
\hline N3 & $1(1.7)$ & $0(0)$ & & $0(0)$ & \\
\hline M stage & & & 0.269 & & 0.664 \\
\hline Negative & $56(93.3)$ & $26(46.4)$ & & $36(64.3)$ & \\
\hline Positive & $4(6.7)$ & $3(75.0)$ & & $3(75.0)$ & \\
\hline CEA (ng/ml) & & & 0.282 & & 0.309 \\
\hline$\leq 5$ & $47(78.3)$ & $21(44.7)$ & & $29(61.7)$ & \\
\hline$>5$ & $13(21.7)$ & $8(61.5)$ & & $10(76.9)$ & \\
\hline AGO2 & & & & & $<0.001$ \\
\hline High & $29(48.3)$ & - & & $27(93.1)$ & \\
\hline Low & $31(51.7)$ & - & & $12(38.7)$ & \\
\hline DGCR8 & & & $<0.001$ & & \\
\hline High & $39(65.0)$ & $27(69.2)$ & & - & \\
\hline Low & $21(35.0)$ & $2(9.5)$ & & & \\
\hline
\end{tabular}

Significant bold values indicate statistical analysis

DGCR8 DiGeorge syndrome critical region gene 8, AGO2 argonaute 2

cutaneous malignant melanoma metastases) and benign melanocytic nevi [26]. Nevertheless, because DGCR8 and $\mathrm{AGO} 2$ are two important components in miRNA maturation, we investigated whether the altered mRNA expression levels of DGCR8 and AGO2 are associated with the carcinogenesis of CRC. As shown in Table 2, no association between altered expressions of the two miRNA machinery components and clinical parameters, including age, tumor stage, CEA titer, and BMI, was revealed. Our result, in agreement with recent study [7], showed no association between DICER, DROSHA, and AGO2 and clinicopathological characteristics. Due to a short follow-up period, we could not assess the prognostic value of each miRNA machinery component in our study group. Therefore, further investigation with longer follow-up period will resume, and prognostic impact of the components will be analyzed as soon as possible.
In this study, we investigated the mRNA expression levels of two selected miRNA machinery components, DGCR8 and AGO2, and their clinical association in CRCs for the first time. Our data demonstrated that DGCR8 is significantly up-regulated in CRC, suggesting that reduced expression of DGCR8 may play an important role during the process of colorectal carcinogenesis. Considering deep correlation between DGCR8 and AGO2 in CRCs, further study of these miRNA components should be needed in various colorectal neoplastic regions.

Acknowledgments This work was supported by Dong-Il Culture and Scholarship Foundation of Korea, 2012. The biospecimens for this study were provided by the Keimyung Human Bio-Resource Bank, a member of the National Biobank of Korea, which is supported by the Ministry of Health and Welfare. All samples derived from the National Biobank of Korea were obtained with informed consent under institutional review board-approved protocols.

Conflict of interest None.

Open Access This article is distributed under the terms of the Creative Commons Attribution License which permits any use, distribution, and reproduction in any medium, provided the original author(s) and the source are credited.

\section{References}

1. Ferlay J, Shin HR, Bray F, Forman D, Mathers C, Parkin DM (2010) Estimates of worldwide burden of cancer in 2008: GLOBOCAN 2008. Int J Cancer 127(12):2893-2917. doi:10. 1002/ijc. 25516

2. Jung KW, Park S, Kong HJ, Won YJ, Lee JY, Seo HG, Lee JS (2012) Cancer statistics in Korea: incidence, mortality, survival, and prevalence in 2009. Cancer Res Treat 44(1):11-24. doi: 10.4143/crt.2012.44.1.11

3. Grade M, Becker H, Liersch T, Ried T, Ghadimi BM (2006) Molecular cytogenetics: genomic imbalances in colorectal cancer and their clinical impact. Cell Oncol 28(3):71-84

4. Li PY, He FC, Zhou GQ (2011) Association of human microRNA related genetic variations with cancer. Yi Chuan 33(8):870-878

5. Schmittgen TD (2008) Regulation of microRNA processing in development, differentiation and cancer. J Cell Mol Med 12(5B):1811-1819. doi:10.1111/j.1582-4934.2008.00483.x

6. Shen J, Stass SA, Jiang F (2012) MicroRNAs as potential biomarkers in human solid tumors. Cancer Lett. doi: 10.1016/j.canlet.2012.11.001

7. Papachristou DJ, Korpetinou A, Giannopoulou E, Antonacopoulou AG, Papadaki H, Grivas P, Scopa CD, Kalofonos HP (2011) Expression of the ribonucleases Drosha, Dicer, and Ago2 in colorectal carcinomas. Virchows Arch 459(4):431-440. doi:10. 1007/s00428-011-1119-5

8. Sand M, Skrygan M, Georgas D, Arenz C, Gambichler T, Sand D, Altmeyer P, Bechara FG (2012) Expression levels of the microRNA maturing microprocessor complex component DGCR8 and the RNA-induced silencing complex (RISC) components argonaute-1, argonaute-2, PACT, TARBP1, and TARBP2 in epithelial skin cancer. Mol Carcinog 51(11):916-922. doi: $10.1002 / \mathrm{mc} .20861$

9. Bartel DP (2004) MicroRNAs: genomics, biogenesis, mechanism, and function. Cell 116(2):281-297 
10. Gregory RI, Yan KP, Amuthan G, Chendrimada T, Doratotaj B, Cooch N, Shiekhattar R (2004) The microprocessor complex mediates the genesis of microRNAs. Nature 432(7014):235-240. doi:10.1038/nature03120

11. Rana TM (2007) Illuminating the silence: understanding the structure and function of small RNAs. Nat Rev Mol Cell Biol 8(1):23-36. doi:10.1038/nrm2085

12. Shaikhibrahim Z, Lindstrot A, Ochsenfahrt J, Fuchs K, Wernert $\mathrm{N}$ (2013) Epigenetics-related genes in prostate cancer: expression profile in prostate cancer tissues, androgen-sensitive and -insensitive cell lines. Int J Mol Med 31(1):21-25. doi:10.3892/ijmm. 2012.1173

13. Zhang X, Cairns M, Rose B, O'Brien C, Shannon K, Clark J, Gamble J, Tran N (2009) Alterations in miRNA processing and expression in pleomorphic adenomas of the salivary gland. Int $\mathbf{J}$ Cancer 124(12):2855-2863. doi:10.1002/ijc.24298

14. Schmittgen TD, Livak KJ (2008) Analyzing real-time PCR data by the comparative $\mathrm{C}(\mathrm{T})$ method. Nat Protoc 3(6):1101-1108

15. Chiosea S, Jelezcova E, Chandran U, Acquafondata M, McHale T, Sobol RW, Dhir R (2006) Up-regulation of dicer, a component of the microRNA machinery, in prostate adenocarcinoma. Am J Pathol 169(5):1812-1820. doi:10.2353/ajpath.2006.060480

16. Mockenhaupt S, Schurmann N, Grimm D (2011) When cellular networks run out of control: global dysregulation of the RNAi machinery in human pathology and therapy. Prog Mol Biol Transl Sci 102:165-242. doi:10.1016/B978-0-12-415795-8. 00006-4

17. Dewi DL, Ishii H, Haraguchi N, Nishikawa S, Kano Y, Fukusumi T, Ozaki M, Saito T, Sakai D, Satoh T, Doki Y, Mori M (2012) Dicer 1, ribonuclease type III modulates a reprogramming effect in colorectal cancer cells. Int J Mol Med 29(6):1060-1064. doi: 10.3892/ijmm.2012.945

18. Faggad A, Kasajima A, Weichert W, Stenzinger A, Elwali NE, Dietel M, Denkert C (2012) Down-regulation of the microRNA processing enzyme Dicer is a prognostic factor in human colorectal cancer. Histopathology. doi:10.1111/j.1365-2559.2011. 04110.x

19. Merritt WM, Lin YG, Han LY, Kamat AA, Spannuth WA, Schmandt R, Urbauer D, Pennacchio LA, Cheng JF, Nick AM, Deavers MT, Mourad-Zeidan A, Wang H, Mueller P, Lenburg
ME, Gray JW, Mok S, Birrer MJ, Lopez-Berestein G, Coleman RL, Bar-Eli M, Sood AK (2008) Dicer, Drosha, and outcomes in patients with ovarian cancer. N Engl J Med 359(25):2641-2650. doi:10.1056/NEJMoa0803785

20. Dedes KJ, Natrajan R, Lambros MB, Geyer FC, Lopez-Garcia MA, Savage K, Jones RL, Reis-Filho JS (2011) Down-regulation of the miRNA master regulators Drosha and Dicer is associated with specific subgroups of breast cancer. Eur $\mathrm{J}$ Cancer 47(1):138-150. doi:10.1016/j.ejca.2010.08.007

21. Faber C, Horst D, Hlubek F, Kirchner T (2011) Overexpression of Dicer predicts poor survival in colorectal cancer. Eur J Cancer 47(9):1414-1419. doi:10.1016/j.ejca.2011.01.006

22. Vincenzi B, Zoccoli A, Schiavon G, Iuliani M, Pantano F, Dell'aquila E, Ratta R, Muda AO, Perrone G, Brunelli C, Correale P, Riva E, Russo A, Loupakis F, Falcone A, Santini D, Tonini G (2013) Dicer and Drosha expression and response to Bevacizumab-based therapy in advanced colorectal cancer patients. Eur J Cancer 49(6):1501-1508. doi:10.1016/j.ejca.2012.11.014

23. Pellegrino L, Jacob J, Roca-Alonso L, Krell J, Castellano L, Frampton AE (2013) Altered expression of the miRNA processing endoribonuclease Dicer has prognostic significance in human cancers. Expert Rev Anticancer Ther 13(1):21-27. doi: 10.1586/era.12.150

24. Jafarnejad SM, Sjoestroem C, Martinka M, Li G (2013) Expression of the RNase III enzyme DROSHA is reduced during progression of human cutaneous melanoma. Mod Pathol. doi: 10.1038/modpathol.2012.225

25. Diaz-Garcia CV, Agudo-Lopez A, Perez C, Lopez-Martin JA, Rodriguez-Peralto JL, de Castro J, Cortijo A, Martinez-Villanueva M, Iglesias L, Garcia-Carbonero R, Fresno Vara JA, GamezPozo A, Palacios J, Cortes-Funes H, Paz-Ares L, Agullo-Ortuno MT (2013) DICER1, DROSHA and miRNAs in patients with non-small cell lung cancer: implications for outcomes and histologic classification. Carcinogenesis. doi:10.1093/carcin/bgt022

26. Sand M, Skrygan M, Georgas D, Sand D, Gambichler T, Altmeyer P, Bechara FG (2012) The miRNA machinery in primary cutaneous malignant melanoma, cutaneous malignant melanoma metastases and benign melanocytic nevi. Cell Tissue Res 350(1):119-126. doi:10.1007/s00441-012-1446-0 